\title{
The local response to the Canadian opioid epidemic in the Kingston, Frontenac, and Lennox and Addington communities
}

\author{
Anees Bahji, MD (1,2,3); Daenis Camiré, MD (4)
}

Tweet this article

\begin{abstract}
Canada is facing a national opioid overdose epidemic, with deaths due to opioid overdoses continuing to rise dramatically. To that end, the opioid experiences of the Kingston, Frontenac, and Lennox and Addington communities, the regional hub for southeastern Ontario and the home of Queen's University, may provide meaningful insights. This article provides a description of recent activities to address the local opioid crisis, a rationale for their adoption and the context in which they are being undertaken.
\end{abstract}

\section{Introduction}

Canada is facing a national opioid overdose epidemic, with deaths due to opioid overdoses continuing to rise dramatically. In 2018, there were 4460 opioid-related deaths, up from 4100 in 2017 and 3017 in 2016. ${ }^{1}$ While British Columbia is currently experiencing the highest death rate in the country, Ontario is a close second with 1471 deaths in 2018. ${ }^{1}$ Four out of five opioid-related deaths in Ontario were accidental, and almost two-thirds of accidental deaths occurred among individuals aged $15-45$ years. $^{2}$

Although the general epidemiology of the Canadian opioid crisis has been extensively described, ${ }^{3-7}$ policy changes at local, provincial and national levels that effectively reduce the community opioid load are less clear. One potential avenue, however, is to learn from the specific responses taken by individual cities. The opioid experiences of the Kingston, Frontenac, and Lennox and Addington (KFLA) communities, the regional hub for southeastern
Ontario and the home of Queen's University, may provide meaningful insights.

In 2018, there were 200 opioid-related emergency department visits, 66 opioidrelated hospitalizations, and 23 opioidrelated deaths, ranking KFLA as the ninth highest for opioid-related deaths out of the 35 Ontario public health regions based on an age/sex-standardized comparison (Figure 1). In 2018, KFLA had a significantly higher per capita rate of opioid prescriptions for pain (109.2 per 1000 population) compared to the provincial average (104.9 per 1000 population). ${ }^{8}$

While these statistics partially quantify the local experience in KFLA, a full discussion of the context for the opioid crisis includes factors such as the contributions of both prescribed and illicit opioids and the role of health professionals in recognizing and addressing opioid use disorder. In recent years, local physicians have been criticized for a perceived failure in their collective ethical responsibility to mitigate their contribution to the problem of

\section{Highlights}

- In 2018, there were 200 opioidrelated emergency department visits, 66 opioid-related hospitalizations, and 23 opioid-related deaths in the Kingston, Frontenac, and Lennox and Addington (KFLA) public health region. Based on an age/sex-standardized comparison, this ranked KFLA as the ninth highest for opioidrelated deaths out of the 35 public health regions in Ontario.

- In response to the local opioid crisis, KFLA has upgraded or launched multiple grassroots organizations, including Street Health Centre, a community-based multidisciplinary addiction service, as well as an inpatient addiction medicine consult team.

- KFLA is rapidly developing into an academic centre of excellence for addiction medicine. The lessons learned locally will help to inform future opioid policy and curriculum design.

prescription opioid misuse. ${ }^{9}$ Health care provider factors, such as fear of causing addiction or physical harm, concerns that a patient is misrepresenting pain, insufficient skills in pain assessment and management, and concern for medication diversion, have been linked to lower rates of opioid prescribing. ${ }^{10}$ Conversely, systemic factors increase opioid prescribing; 


\section{FIGURE 1}

Cases of opioid-related morbidity and mortality, Kingston, Frontenac and Lennox and Addington Public Health, 2003-2018

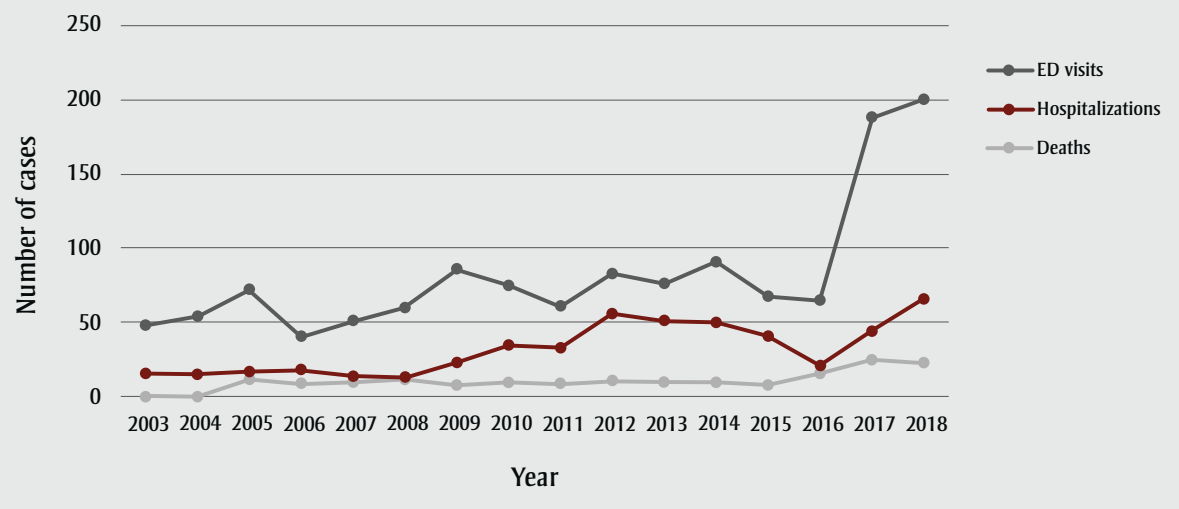

Source: Ontario Agency for Health Protection and Promotion (Public Health Ontario). Interactive opioid tool. Toronto (ON): Queen's Printer for Ontario; 2019. Available from: https://www.publichealthontario.ca/en/data-and-analysis/substance-use /interactive-opioid-tool

Abbreviation: ED, emergency department.

these include limited access to training in pain and addiction management, lack of continuity of care and decreased availability of non-opioid analgesics. ${ }^{11}$ Training factors, such as the academic rank and region of medical schools, have also been associated with the specific patterns of opioid prescribing by physicians working in the same specialties and clinical settings. ${ }^{12}$

Canada has one of the highest usage rates of prescription opioids in the world. ${ }^{13} \mathrm{~A}$ recent national environmental scan conducted by the Association for the Faculties of Medicine of Canada in 2017 found that only one-third of medical schools met best practice standards for minimum mandatory training in pain and opioid management. ${ }^{14}$ Specifically, none of Queen's University's residency programs outside of family medicine met best practice guidelines across undergraduate, postgraduate or continuing professional development levels. ${ }^{14}$ The intention of the report was by no means punitive, but rather to illustrate how only a small proportion of Canadian medical schools have integrated pain courses in their curriculum (with the median number of hours spent on pain and pain management often being less than 10 hours in total across 4 years of training). ${ }^{14}$

\section{Resources}

In response to growing concerns, multiple grassroots efforts have taken shape in
Kingston. Street Health Centre-a multidisciplinary, community-based, low-barrier resource for marginalized individuals with addiction-related needs-has enhanced their offering of addictions services. ${ }^{15}$ Current services include primary care physicians; psychiatrists; a rapid access addiction medicine clinic that provides opioid-agonist medications like methadone and buprenorphine in a timely manner; an opioid overdose prevention site; a needle and syringe exchange program; a hepatitis and HIV treatment clinic; social work; psychology; counselling; and even an inhouse pharmacy. ${ }^{15}$

At the hospital level, a multidisciplinary addiction medicine consult team (AMCT) consisting of physicians, social workers, case managers, residents, medical students and peers was initiated in 2017. ${ }^{16}$ Early on, the AMCT conducted a needs assessment to identify the specific addictions concerns of inpatient physicians. ${ }^{16}$ This needs assessment led to the current mandate of diagnosing, treating and engaging patients who are at risk for addiction-related medical concerns. To date, the AMCT has forged collaborations with Public Health Ontario, the Canadian Society for Addiction Medicine, the Canadian Centre on Substance Use and Addiction, the Canadian Research Data Centre Network, the Ontario Drug Policy Research Network, MetaPhi, Health Quality Ontario, the Centre for Addiction and Mental Health, and the Canadian Medical Association.
By partnering with these organizations, there has been a significant increase in the dissemination of opioid-relevant health policy and evidence-based recommendations categorized across the four pillars of effective opioid policy-prevention, treatment, harm reduction and enforcementintelligence. ${ }^{17,18}$ Several meaningful themes have emerged:

- An emphasis on documenting discussions with patients that nonpharmacological therapy and non-opioid analgesics are preferred for chronic non-cancer pain over long-term opioid therapy; ${ }^{19}$

- Prescribing the lowest effective dosage of opioid medication, with careful documentation and additional reassessments if the dose exceeds 50 morphine milligram equivalents (MME) per day; doses should not exceed 90 MME per day (unless there are special circumstances); ${ }^{20}$

- In ED settings, if opioid prescriptions must be provided-particularly to opioidnaive patients - they should be short in duration and for lower daily doses; ${ }^{19}$

- Developing partnerships between primary care, EDs and addictions specialists to maintain continuity of care and sharing of health information systems;

- Providing increased opportunities for physician and allied health education in opioid-related medicine; ${ }^{6}$

- Increasing the availability of referrals for harm reduction and addiction treatment; 21

- Providing take-home naloxone kits and overdose prevention education liberally; and

- Documenting the risk of opioid overdose using appropriate, clinically validated evaluation tools or instruments. ${ }^{22}$

These guidelines seem to have been particularly well-received by busy local physicians as they are often structured algorithmically, which enables users to match a particularly challenging clinical encounter with a set of targeted best practices. For example, when a patient's total opioid dosage reaches or exceeds $50 \mathrm{MME} /$ day, the guidelines describe how the risk of experiencing a fatal opioid overdose is increased by at least two-fold. In this particular example, the guidelines would then prompt the clinician to evaluate the potential for opioid tapering, to implement additional precautions, to increase the 
frequency of follow-up, to dispense takehome naloxone kits and to provide additional opioid overdose prevention education to both the patient and their household members.

\section{Challenges}

Despite recent evidence suggesting that opioid stewardship programs have the potential to lower costs and improve patient outcomes and satisfaction with care, ${ }^{23,24}$ surveys of Canadian family physicians and pharmacists have found significant gaps in their knowledge and uptake of evidence-based pain management and guidelines on safe opioid prescribing. ${ }^{20,25}$ As well, institutional barriers have limited the implementation of best practices largely from the scarcity of physicians trained in addiction and pain management, the bottlenecking of outpatient services and a lack of dedicated educational infrastructure. ${ }^{5}$

\section{The way forward}

Despite these challenges, several potential strategies exist to address ongoing opioidrelated problems. A persistent focus on disseminating pain and addiction management training-as well as guidelines on safe opioid prescribing-will be crucial to reducing the risk of accidental overdose and iatrogenic opioid addiction. ${ }^{6}$ The inclusion of pain management training in medical school curricula could also mitigate some of these challenges. ${ }^{26}$ Supporting local resources and front-line staff will play an instrumental role in providing the best care available to those who have opioid-related needs. Although opioid risk assessment tools and treatment contracts have been used to stratify patient risk and prevent opioid overuse in patients who are at risk for dependence, there is little evidence to support suggestions that they actually have an impact on opioid prescribing. ${ }^{27-29}$

Additional research is needed to explore the longer-term impacts of local programs on opioid culture and local resource utilization among KFLA health care providers, including physicians, allied health practitioners, front-line staff and individuals with opioid experience. For example, Queen's University launched a series of online opioid training modules that were paired with a set of pre- and post-module survey questionnaires. The effectiveness of this educational module at informing changes in prescribing attitudes via rates of opioid prescribing, will be monitored over time. Utilization of local harm reduction services-overdose prevention sites, take-home naloxone and educational interventions-is actively measured, providing the means for ongoing feedback about ways of improving resources delivery for patients and front-line staff. There also remains a great need to understand the local perspectives of patients, particularly regarding the risks of opioids, including opioid-impaired driving, the effectiveness of co-prescription of naloxone with opioid analgesics in preventing opioid overdose deaths and the impact of overdose prevention sites. Identifying-and removinglocal barriers to optimal addiction care will empower Kingston-based physicians in their efforts to deliver evidence-based interventions.

\section{Conflicts of interest}

The authors have no conflicts of interest to declare.

\section{References}

1. Special Advisory Committee on the Epidemic of Opioid Overdoses. National report: apparent opioid-related deaths in Canada (released June 2018) [Internet]. Ottawa (ON): Public Health Agency of Canada; 2018 Jun [modified 2018 Dec 13; cited 2019 Jan 4]. Available from: https://www.canada.ca /en/public-health/services/publications /healthy-living/national-report-apparent -opioid-related-deaths-released-june -2018.html

2. Ontario Agency for Health Protection and Promotion (Public Health Ontario). Interactive opioid tool: opioid-related morbidity and mortality in Ontario [Internet]. Toronto (ON): Queen's Printer for Ontario; [cited 2019 Jul 12]. Available from: https://www .publichealthontario.ca/en/data-and -analysis/substance-use/interactive -opioid-tool

3. Dyer O. Canada's prescription opioid epidemic grows despite tamperproof pills. BMJ. 2015;351:h4725. doi: 10.1136 /bmj.h4725.

4. Alam A, Juurlink DN. The prescription opioid epidemic: an overview for anesthesiologists. Can J Anaesth. 2016; 63(1):61-8. doi:10.1007/s12630-015 $-0520-y$.
5. Bahji A, Bajaj N. Opioids on trial: a systematic review of interventions for the treatment and prevention of opioid overdose. Can J Addict. 2018;9(1):2633. doi:10.1097/CXA.0000000000000013.

6. Bahji A, Camiré D. Letter to the editor: a case for opioid education and training for medical students, residents, and allied health staff: response to "Educational Intervention for physicians to address the risk of opioid abuse.” J Opioid Manag. 2018; 14(3):157. doi:10.5055/jom.2018.0452.

7. Baird J, Faul M, Green TC, et al. A retrospective review of unintentional opioid overdose risk and mitigating factors among acutely injured trauma patients. Drug Alcohol Depend. 2017; 178:130-5. doi:10.1016/j.drugalcdep .2017 .04 .030 .

8. Ontario Drug Policy Research Network. Ontario prescription opioid tool [Internet]. Toronto (ON): ODPRN; $2018 \mathrm{Jul}$ [cited 2019 Jul 8]. Available from: https://odprn.ca/ontario-opioid-drug -observatory/ontario-prescription -opioid-tool/

9. Vogel L. Proposed opioid prescribing guidelines meet backlash. CMAJ. 2017; 189(7):E290-1. doi:10.1503/cmaj .1095393 .

10. Bohnert AS, Valenstein M, Bair MJ, et al. Association between opioid prescribing patterns and opioid overdose-related deaths. JAMA. 2011; 305(13):1315-21. doi:10.1001/jama .2011 .370

11. Dowell D, Haegerich TM, Chou R. CDC guideline for prescribing opioids for chronic pain - United States, 2016. MMWR Recomm Rep. 2016;65(1):149. doi:10.15585/mmwr.rr6501e1.

12. Gomes T, Juurlink D, Moineddin R, et al. Geographical variation in opioid prescribing and opioid-related mortality in Ontario. Healthc Q. 2011;14(1): 22-4. doi:10.12927/hcq.2011.22153.

13. Degenhardt L, Charlson F, Mathers B, et al. The global epidemiology and burden of opioid dependence: results from the global burden of disease 2010 study. Addiction. 2014;109(8): 1320-3. doi:10.1111/add.12551.

14. Association of Faculties of Medicine of Canada. Final report on the AFMC response to the Canadian opioid crisis. Ottawa (ON): AFMC; 2017. 
15. Street Health Centre [Internet]. Kingston (ON): Kingston Community Health Centres; [cited 2019 Jun 1]. Available from: http://www.kchc.ca/street-health -centre/

16. Bahji A, Lusty E, Majere R, Newman A, Reshetukha T, Carvalhal A. Piloting an addictions medicine consultation team in Kingston, Ontario, Canada: Results of an Inpatient needs assessment. Can J Addict. 2019;10(1): 29-32. doi:10.1097/CXA.0000000000 000047.

17. Belzak L, Halverson J. The opioid crisis in Canada: a national perspective. Health Promot Chronic Dis Prev Can. 2018;38(6):224-33. doi:10.24095/hpcdp 38.6.02.

18. Bruneau J, Ahamad K, Goyer MÈ, et al. Management of opioid use disorders: a national clinical practice guideline. CMAJ. 2018;190(9):E247-57. doi:10.1503/cmaj.170958.

19. Rickert J, Devlin K, Krohn K. Comprehensive care of pain: developing systems and tools to improve patient care and resident education. Int J Psychiatry Med. 2016;51(4):33746. doi:10.1177/0091217416659270.

20. Broad K, Colon-Rivera HA, Haque L. Opioid agonist therapy. Can Fam Physician. 2017;63(7):509-10.

21. Hyshka E, Anderson-Baron J, Pugh A, et al. Principles, practice, and policy vacuums: policy actor views on provincial/territorial harm reduction policy in Canada. Int J Drug Policy. 2019 Jan 30 [in press]; doi:10.1016/j.drugpo .2018.12.014

22. Webster LR, Webster RM. Predicting aberrant behaviors in opioid-treated patients: preliminary validation of the Opioid Risk Tool. Pain Med. 2005; 6(6):432-42. doi:10.1111/j.1526-4637 .2005.00072.x.

23. Perrone J, Weiner SG, Nelson LS. Stewarding recovery from the opioid crisis through health system initiatives. West J Emerg Med. 2019;20(2): 198-202. doi:10.5811/westjem.2018.11 .39013 .
24. Patrick SW, Fry CE, Jones TF, Buntin MB. Implementation of prescription drug monitoring programs associated with reductions in opioid-related death rates. Health Aff (Millwood). 2016; 35(7):1324-32. doi:10.1377/hlthaff 2015.1496 .

25. Dubin RE, Kaplan A, Graves L, Ng VK. Acknowledging stigma: its presence in patient care and medical education. Can Fam Physician. 2017; 63(12):906-8.

26. Leo RJ, Pristach CA, Streltzer J. Incorporating pain management training into the psychiatry residency curriculum. Acad Psychiatry. 2003; 27(1):1-11. doi:10.1176/appi.ap.27.1.1.

27. Anghelescu DL, Ehrentraut JH, Faughnan LG. Opioid misuse and abuse: risk assessment and management in patients with cancer pain. J Natl Compr Canc Netw. 2013;11(8): 1023-31. doi:10.6004/jnccn.2013.0120.

28. Daoust R, Paquet J, Moore L, et al. Incidence and Risk factors of longterm opioid use in elderly trauma patients. Ann Surg. 2018;268(6):98591. doi:10.1097/SLA.0000000000002461.

29. Brown J, Setnik B, Lee K, et al. Assessment, stratification, and monitoring of the risk for prescription opioid misuse and abuse in the primary care setting. J Opioid Manag. 2011;7(6):467-83. doi:10.5055/jom .2011 .0088 . 